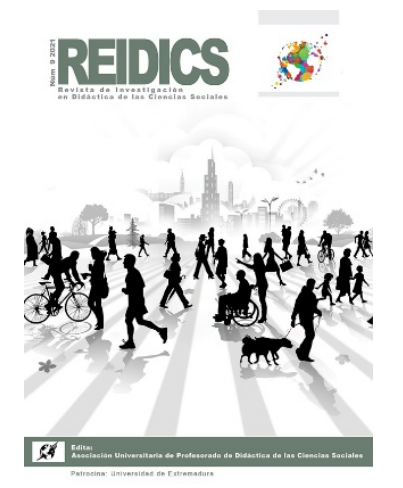

\title{
REIDICS
}

Revista de Investigación en

Didáctica de las Ciencias

Sociales
Núm. 9, 2021

Recibido 05 diciembre de 2020

Aceptado 15 de febrero de 2021

E-ISSN: 2531-0968

\section{¿"Ellos" o "nosotros"? prejuicios y estereotipos sobre los musulmanes en el alumnado preadolescente}

\section{"Them" or "us"? prejudices and stereotypes about muslims in pre-adolescent students}

Beatriz Andreu-Mediero

Universidad de Las Palmas de Gran Canaria

Email: beatriz.andreu@ulpgc.es

ORCID: https://orcid.org/0000-0002-2351-2880

Imane Ouhamid-Zahri

Universidad de Las Palmas de Gran Canaria

Email: ima.ouhamid.z@gmail.com

DOI: https://doi.org/10.17398/2531-0968.09.152

\section{Resumen}

Los objetivos de este trabajo son los de analizar la presencia de prejuicios y estereotipos en torno a los musulmanes, en un grupo de estudiantes de 6 o de Primaria, y reflexionar sobre la importancia de detectarlos, pensarlos y combatirlos, por su influencia en la conformación de la identidad personal y colectiva desde la enseñanza de la historia. Con una metodología de investigación mixta, se recogen las actitudes y opiniones de una muestra compuesta por 107 alumnos, musulmanes y no musulmanes, de dos centros educativos de Canarias. El instrumento de investigación, elaborado para esta investigación, es un cuestionario que cuenta con 11 ítems con escala de valoración tipo Likert, que se han analizado con Excel, y una pregunta abierta que se ha categorizado y ha permitido su triangulación. Los resultados muestran una relativa presencia de prejuicios y estereotipos negativos entre este alumnado, quizá por el contexto histórico y social asociado a la muestra. Estos están vinculados a la generalización y confusión de términos y de significados, los cuales están presentes y se transmiten por los medios de comunicación y la educación histórica, interviniendo en la conformación de la identidad personal y colectiva.

Palabras clave: enseñanza de la historia; identidad; identidad cultural; estereotipos; islam.

\section{Abstract}

The objectives of this work are to analyse the presence of prejudices and stereotypes about Muslims in a group of 6th grade primary school students and to reflect on the importance of 
detecting, thinking about and combating them, due to their influence on the formation of personal and collective identity from the perspective of the teaching of history. Using a mixed research methodology, the attitudes and opinions of a sample of 107 students, both Muslim and non-Muslim, from two schools in the Canary Islands are collected. The research instrument, developed for this investigation, is a questionnaire with 11 items with a Likerttype assessment scale, which have been analysed with Excel, and an open question which has been categorised and allowed for triangulation The results show a relative presence of prejudices and negative stereotypes among this student body, perhaps due to the historical and social context associated with the sample. These are linked to the generalisation and confusion of terms and meanings, which are present and transmitted by the media and historical education, intervening in the shaping of personal and collective identity.

Keywords: history teaching; identity; cultural identity; stereotypes; islam.

\section{Introducción}

Nuestra identidad personal está compuesta por todo aquello que sentimos que somos en relación con una diversidad de pertenencias, pues la vamos construyendo a través de la "herencia" vertical, vinculada a nuestros antecesores, y a la horizontal de nuestros contemporáneos, así como con las elecciones que hacemos a lo largo de la vida (Maalouf, 2009). La identidad se construye en la relación con el "otro", en la búsqueda por la identificación positiva de la imagen de uno mismo y del rechazo ante lo "negativo" de los demás y, en esta construcción identitaria, juegan un papel esencial los prejuicios y los estereotipos. Según la teoría psicosocial de Erikson (Bordignon, 2005), la adolescencia es el momento más crítico, pues es cuando los adolescentes buscan "su" identidad, tratando de saber quiénes son, consolidando una imagen positiva de ellos mismos para sentirse parte de un grupo con el que identificarse (Mercado y Hernández, 2010). En esta construcción intervienen las experiencias vividas, el entorno en el que han crecido y los mensajes que les llegan a través de los medios de comunicación y la escuela, de forma que los prejuicios y estereotipos presentes en las experiencias de la niñez y de la propia adolescencia podrán incidir en la intensidad de la crisis que los adolescentes pudieran llegar a tener. En este punto, destacaba Erikson (1972), que la migración suele tener un gran peso en la construcción de la identidad, máxime cuando a esta se le añade el componente religioso.

El incremento de los discursos nacionalistas dificulta el desarrollo desde Europa de una ciudadanía basada en la democracia y en los derechos humanos, en la que se acabe con los prejuicios y estereotipos y que promueva una identidad construida sobre la base de la inclusión respecto a la diversidad cultural (Marín, 2002), consciente de los valores compartidos y también de las diferencias (Bartolomé y Cabrera, 2003; Rodríguez-Lestegás, 2008), de forma que se camine hacia una ciudadanía global (Pagès, 2019). Vivimos en sociedades multiculturales y Moreras (2004) destaca que en el momento en el que se incorporó el factor religioso a la migración, se agudizó la visión problemática de la misma, lo que coincide con la percepción negativa, prejuiciosa y estereotipada que está presente en el discurso histórico sobre el islam, los musulmanes y el mundo árabe, imposibilitándose así la configuración de una identidad común y consolidándose el “ellos” frente al “nosotros" (López, 2013; Martín 1998; 2012; Moreras 2017). 
La migración incide en la identidad porque el abandono del territorio por parte del migrante tiene consecuencias emocionales (Erikson, 1972; Maalouf, 2009), que pueden agravarse en el caso de la segunda generación de inmigrantes, aunque hayan nacido en el territorio de acogida. Esto se debe a que llevarán consigo las dos pertenencias, la del lugar de nacimiento y la de la procedencia familiar, y dependerá, además, de las experiencias vividas. Tal es el caso del desarraigo de los jóvenes musulmanes en Europa del que habla Maalouf (2009), ya que no pertenecen a la sociedad europea pero tampoco a las de sus antecesores y esto puede dar lugar a crisis de identidad (Abu Zayd, 2012).

España el 4\% de la población española es musulmana y se encuentra en todas las comunidades (Observatorio Andalusí, 2020). Dicha población puede estar conformada por inmigrantes o españoles descendientes de inmigrantes, muchos de los cuales están en nuestras aulas. En este marco, resulta esencial tener en cuenta la incidencia de la migración en la conformación de las identidades, incluyendo a los descendientes de los inmigrantes, ya que, la doble pertenencia puede suponer un enriquecimiento o una tragedia para la identidad de estas personas, en función de la experiencia que hayan tenido (Maalouf, 2009).

En un escenario como este, la educación requiere de una reflexión y una acción por parte de todos los actores implicados que atienda las múltiples necesidades que surgen durante la conformación de la identidad personal, colectiva y cultural del alumnado de Primaria y Secundaria. Además, las narrativas históricas escolares siguen estando vinculadas, en mayor o menor medida, al desarrollo identitario de las sociedades, pues incluye "elementos cognitivos, imaginarios y emocionales" (Valls, 2011, p. 77). Así, en la línea de lo expuesto por Valls (2012), Sáiz y López (2012), consideramos que se debe reflexionar sobre la relación entre historia e identidad, lo cual constituye uno de los objetivos de este trabajo, junto con el de analizar los prejuicios y estereotipos negativos en torno a los musulmanes y el islam, que pudieran estar presentes en un grupo de estudiantes de $6^{0}$ de Primaria de dos centros educativos.

\section{Prejuicios y estereotipos en torno al islam}

Los prejuicios y los estereotipos son ideas simples que están presentes en nosotros, consciente o inconscientemente, y nos llegan a través de diferentes canales que constituyen la memoria colectiva. Los prejuicios surgen porque el pensamiento humano necesita ordenar y clasificar la realidad en categorías que guíen las actuaciones diarias (Casas, 1999). Los estereotipos forman parte del prejuicio (Alaminos-Fernández y Alaminos-Fernández, 2020; Alaminos-Fernández y Alaminos-Fernández, 2012) siendo "el conjunto de ideas que nos proporcionan una imagen, si bien simple, que pretende caracterizar el comportamiento de las personas que componen una determinada categoría" (Del Olmo, 2005, p. 16). Pueden tener una connotación positiva o negativa, en función de los atributos asociados a la imagen que se tenga del elemento, característica o individuo, aunque cuando el prejuicio es étnico, suele tener una connotación negativa (Allport, 1981).

Si bien Said (2003) comenzó a denunciar los prejuicios y estereotipos en torno a lo Oriental, al mundo árabe y al islam en Occidente tras la crisis de 1973, el discurso islamófobo se generalizó tras los atentados de 2001 en Estados Unidos y de 2004 en España. A través de frases sencillas, a 
modo de eslóganes, los prejuicios y estereotipos negativos van calando en la sociedad (Durán 2019; Martín, 2005; 2012; Martín y Grosfoguel, 2012; van Dijk, 2008), en torno a noticias relativas a inmigración y/o terrorismo (Rodrigues de Mendonça y Rodríguez-Díaz, 2017). Así, Durán (2019) establece tres elementos que caracterizan la islamofobia: los intentos por homogeneizar el islam como un todo en el que todos los conceptos se entremezclan; promover un enfoque de exclusión; y ofrecer una imagen de los musulmanes y del islam como problema.

Diversos estudios (Alcántara-Pla y Ruiz-Sánchez, 2017; Durán, 2019; Observatorio Andalusí, 2019; Moualhi, 2000; Navarro, 2002; van Dijk, 2008), muestran cómo desde los medios de comunicación se tiende a remarcar el discurso negativo del "ellos", que en los conflictos adquiere la connotación de los "malos" o los "culpables", frente al "nosotros", los "buenos", las "víctimas", o los portadores de una identidad superior (Maalouf, 2009). Van Dijk (2008, p. 19) hace referencia al vocabulario utilizado al referirse a la llegada de inmigrantes -ola, avalancha, invasión, etc.-, para continuar con un amplio espectro de características que constituyen el "racismo discursivo anti-islam", pues, la visión que los medios suelen dar de los migrantes se ciñe a la de la migración que no sigue los cauces legales y que llega por mar a través de pateras, cuando la entrada a España de esta forma es minoritaria (Kem-Mekah, 2016). Van Dijk (2008), destaca la consolidación de prejuicios y estereotipos producida por esa generalización del "ellos" enfocándose en lo negativo, pero, sobre todo, en la confusión de los términos relativos a árabes, musulmanes, islámicos, o islamistas; en la falta de conocimiento de sus culturas; en el recurso a los estereotipos como violentos, agresivos, primitivos, atrasados o machistas, y en el uso del hiyab en las mujeres musulmanas, percibiéndolas "como delincuentes o cómplices pasivas del islamismo radical" (Geisser, 2012, p. 67), asimiladas a "lo tradicional", sin explicar las causas por las que una mujer puede decidir llevar un pañuelo en sus diferentes variantes (Navarro, 2002). Como dice Moudalhi (2000), admitir la imagen distorsionada que se da de las mujeres, no quiere decir que no haya discriminación en los países de origen, sino que es una realidad simplificada que lleva a la generalización de estereotipos.

La enseñanza de la historia ha recogido las narrativas históricas en las que se fomentaba la construcción de una identidad nacional a través de la memoria colectiva (Carretero et al. 2013; Carretero y Montanero, 2008), y el papel que el islam ha jugado en ese proceso ha sido el del adversario amenazante para la identidad europea y occidental a través de la propagación de prejuicios y estereotipos. En este sentido, la historiografía oficial promovió una identidad nacional española marcada por una versión del islam vinculada a Al-Andalus, desde un discurso de confrontación en el que se hablaba en términos de "pérdida" y "reconquista", de un "nosotros", contra un "ellos", y que ha estado presente desde la Edad Media hasta la actualidad (Manzano, 2011; Martín, Valle y López, 1996; Martín, 1998; 2005; Parra, 2007; Sáiz y López, 2012).

Esta visión de confrontación y superioridad con respecto al islam se mantuvo durante el Franquismo y el final de la Dictadura no produjo un gran cambio. Algunos investigadores (Martín, Valle y López, 1996; Martín, 1998; 2005; Parra, 2007; Saleh, 2008) han denunciado desde finales del siglo XX la visión que los libros de texto de historia ofrecían sobre el islam y los musulmanes, en los que se hablaba de Al-Andalus o de la presencia de los musulmanes durante este periodo con una connotación distante y de provisionalidad, como si no formaran parte de una identidad 
cultural vinculada a España, pese a la imagen más integrada que parece que se ha observado en los últimos años (Valls, 2012).

En un estudio llevado a cabo por European Monitoring Centre on Racism and Xenophobia (Choudhury et al., 2006), se observó que la islamofobia parece que es percibida por las distintas generaciones de musulmanes en los países europeos, en mayor o menor medida, tengan la ciudadanía o no, sintiéndose excluidos de la vida social, política y económica de Europa, a través de los prejuicios y estereotipos presentes en los medios de comunicación y en las escuelas. La educación histórica y los medios de comunicación son, por tanto, las principales vías a través de las cuales se promueven opiniones, actitudes y emociones, lo que se traduce en prejuicios y estereotipos sobre la realidad social, en general, y sobre el mundo árabe y el islam, en particular. En esta línea, hay interesantes investigaciones que plantean combatir los discursos hegemónicos en estos medios a través de la literacidad crítica (Atienza, 2007; González-Monfort y Santisteban, 2020; Santisteban, Díez-Bedmar y Castellví, 2020).

\section{Metodología}

Los objetivos de este trabajo son los de analizar la presencia de prejuicios y estereotipos en torno a los musulmanes, en un grupo de estudiantes de $6^{0}$ de Primaria, y reflexionar sobre la importancia de detectarlos, pensarlos y combatirlos, por su influencia en la conformación de la identidad personal y colectiva desde la enseñanza de la historia. Para ello, se ha llevado a cabo una investigación de tipo mixto.

La muestra está compuesta por un total de $n=107$ alumnos y alumnas, con edades entre los 11 y 12 años, respondiendo a un muestreo no probabilístico y por conveniencia. Este alumnado, al encontrarse en 6 ${ }^{\circ}$ curso, ha trabajado en cursos precedentes con contenidos conceptuales de historia de España que, según el currículo, van desde la Prehistoria hasta le Edad Moderna y Contemporánea. Pertenecen a dos centros educativos públicos ubicados en la zona costera del municipio de Santa Lucía de Tirajana, en la isla de Gran Canaria, Canarias y, entre el alumnado hay 17 alumnos y alumnas que son musulmanes, siendo el resto no musulmán.

\subsection{Descripción de los participantes}

El lugar de nacimiento de la muestra refleja (Figura 2) que la mayoría ha nacido en España, aunque hay inmigrantes de procedencias diversas. En cuanto a los musulmanes, su lugar de nacimiento es España, con la excepción de dos que nacieron en Marruecos.

El origen de los progenitores del alumnado (Figura 3), revela que, si bien la mayoría ha nacido en España, también hay otras procedencias, entre las que desatacan los nacidos en Marruecos. Así, uno o los dos progenitores del alumnado musulmán son de origen marroquí, salvo en el caso de tres alumnos que tanto ellos como sus padres han nacido en España, lo que podría deberse a que, o bien sus antepasados fueron inmigrantes, o bien profesan la fe por otro tipo de causa. 


\section{Figura 1}

Países de origen del alumnado

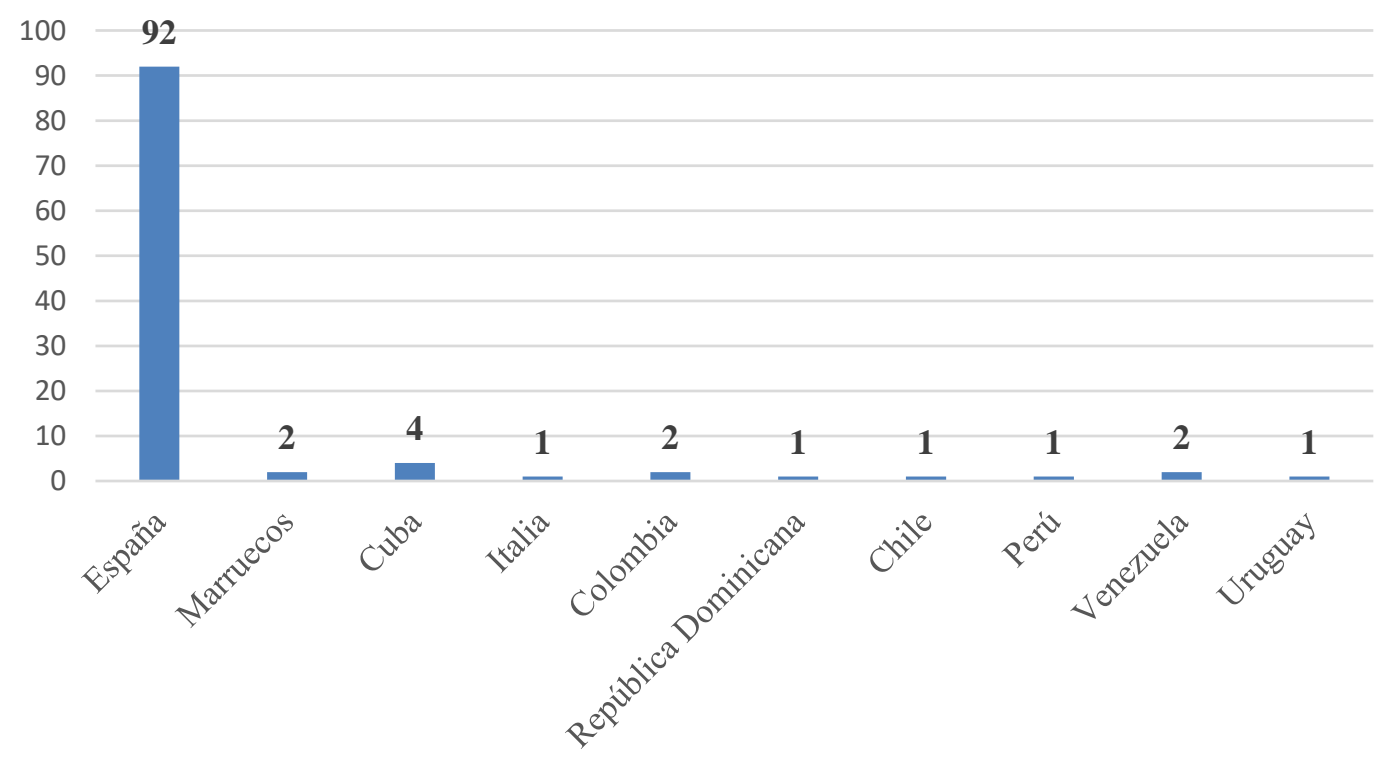

\section{Figura 2}

Países de origen de los progenitores del alumnado

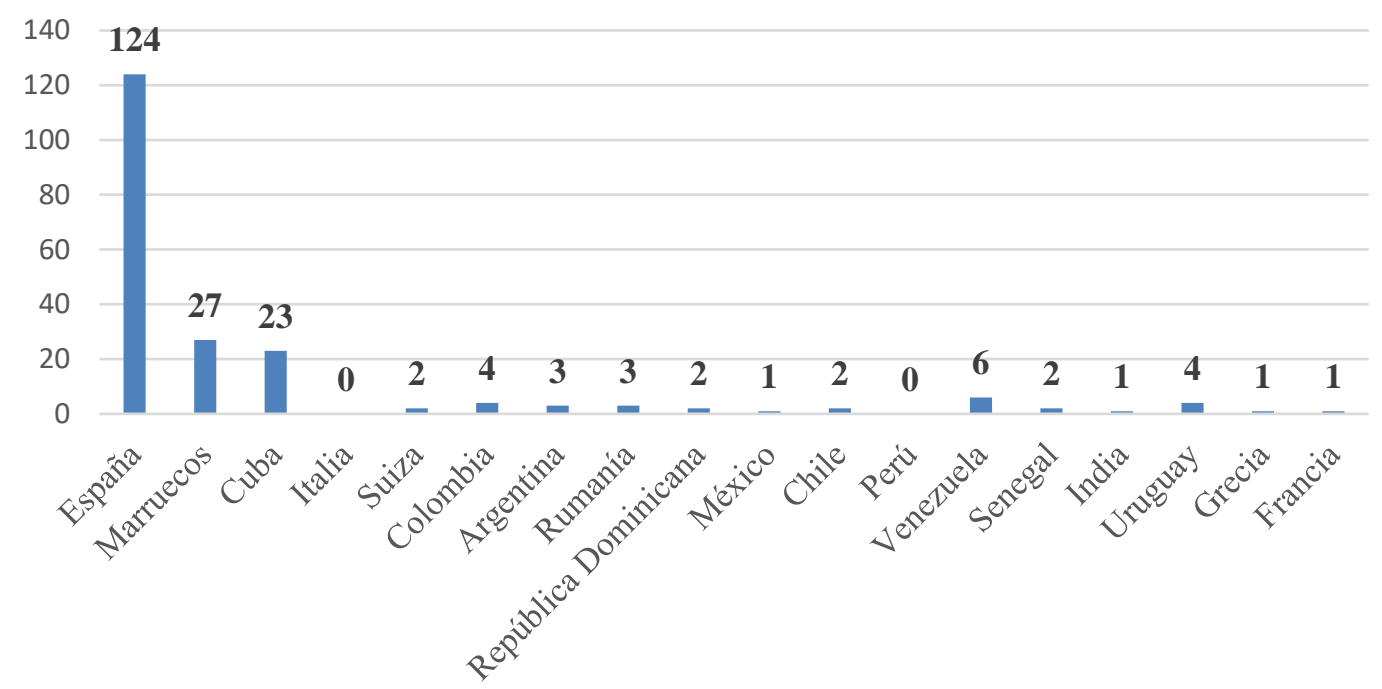

\subsection{Plan de análisis}

El instrumento de investigación utilizado ha sido un cuestionario diseñado para trabajar en esta experiencia y pretende analizar la presencia o no de prejuicios y estereotipos sobre los musulmanes en este alumnado. Presenta once ítems relativos a preguntas cerradas, basadas en escalas de actitud tipo Likert, como instrumento psicométrico para responder a su grado de acuerdo o desacuerdo ante una afirmación, y una pregunta abierta para plasmar su visión de los musulmanes. Los ítems se agrupan en cuatro categorías: (1) estereotipos negativos en torno a los musulmanes; (2) prejuicios vinculados a cuestiones culturales; (3) prejuicios del alumnado con respecto a las relaciones con los musulmanes; (4) un ítem relativo a un prejuicio que no pretende 
tanto saber si está presente en el alumnado, sino si lo han escuchado. La escala de actitud tipo Likert es de 3 puntos o rangos, en formato numérico y gráfico, donde 1 supone estar en desacuerdo, 2 ni de acuerdo ni en desacuerdo, "no lo sé”, y 3 supone estar totalmente de acuerdo, por lo que se puede medir la actitud, pero no la intensidad, al tener solo un valor positivo y uno negativo. Se ha optado por esta escala de 3 puntos debido a que se ha considerado que era la opción más sencilla para niños y niñas de Primaria, ante una temática delicada. Habrá que tener en cuenta que la opción intermedia, neutral o de indecisión (2), puede ser más utilizada en este tipo de escalas (García, Aguilera y Castillo, 2011; Morales, 2011), motivo por el cual el cuestionario presenta, además, una pregunta abierta que permita triangular los aspectos reseñados en los ítems de los grupos 1, 2 y 3, facilitando la interpretación de resultados a favor de una visión más concreta de la percepción que el alumnado tiene de los musulmanes y el islam.

Desde el punto de vista cuantitativo, se ha procedido a un estudio descriptivo para obtener frecuencias de respuestas en torno a las cuatro temáticas, recurriéndose al programa Excel para el análisis de los datos y para presentar las gráficas que agrupan las diversas variables, mostrándose, a su vez, los resultados de la escala Likert. Desde el cualitativo, se ha recurrido al análisis categorizado de la percepción del alumnado (Flick, 2015; Sabariego y Bisquerra, 2012), pues la pregunta abierta ofrecía como respuesta la mención de diferentes características por parte del alumnado, que se han agrupado en cuatro dimensiones, observándose, además la frecuencia de coincidencia de cada uno de los términos o ideas, de forma que este último punto se muestra en nube de palabras mediante la aplicación WordItOut.

Como los ítems presentan opciones de respuesta que pueden ser positivas o negativas, inicialmente se procedió a su tabulación, para, posteriormente, comenzar con el análisis, el cual queda estructurado en tres partes (Tabla 1 ).

En la primera parte se ha recurrido al análisis cuantitativo general para establecer las frecuencias que permitan una aproximación al nivel de prejuicios y estereotipos presente en la muestra. Para ello se ha obtenido una categorización jerárquica de los resultados, agrupándose en tres categorías proporcionales para indicar el nivel de prejuicios y estereotipos que parecen estar presentes entre el alumnado. En la segunda parte se realiza un análisis de los cuatro grupos establecidos en torno a la presencia de prejuicios y estereotipos negativos $(1,2,3$ y 4), compuesto por las once variables categóricas ordinales. Solo el grupo 3 presenta la distinción gráfica de respuestas entre alumnado musulmán y no musulmán. Por último, la tercera parte responde al análisis cualitativo de las respuestas a la pregunta abierta, a través del cual se muestra la cuantificación de términos e ideas mediante una nube de palabras, así como las cuatro dimensiones en las que se han agrupado estos términos e ideas de los estudiantes: (a) religiosa, (b) cultural, (c) de personalidad y (d) fenotípica, diferenciando, en ambos casos, musulmanes de no musulmanes. 


\section{Tabla 1}

Estructura del análisis y de presentación de los resultados

\begin{tabular}{l}
\hline Análisis ítems cuantitativos: \\
\hline 1a $^{\text {a }}$ parte: Nivel de prejuicios y estereotipos general presente en el alumnado \\
$2^{\text {a }}$ parte: Análisis de ítems cuantitativos agrupados en torno a: \\
Grupo (1): Estereotipos negativos en torno a los musulmanes \\
Grupo (2): Prejuicios vinculados a cuestiones culturales \\
Grupo (3): Prejuicios presentes en las relaciones con los musulmanes \\
Grupo (4): Prejuicios ajenos al alumnado y que pueden haber escuchado
\end{tabular}

\section{Análisis ítem cualitativo:}

3- Parte:

- Frecuencias de características utilizadas, mostrado en nubes de palabras

- Agrupación de las características para definir a los musulmanes en:
(a) Dimensión religiosa
(b) Dimensión cultural
(c) Dimensión de personalidad
(d) Dimensión fenotípica

Fuente: Elaboración propia

\section{Resultados}

La lectura obtenida tras la categorización de los datos advierte que el nivel de prejuicios y estereotipos en la muestra es relativo, pues algo menos de la mitad parece que presenta algunos prejuicios y estereotipos negativos, con la excepción de un $2 \%$ del alumnado que sí presenta muchos.

\section{Figura 3}

Nivel de prejuicios y estereotipos que presenta el alumnado de la muestra

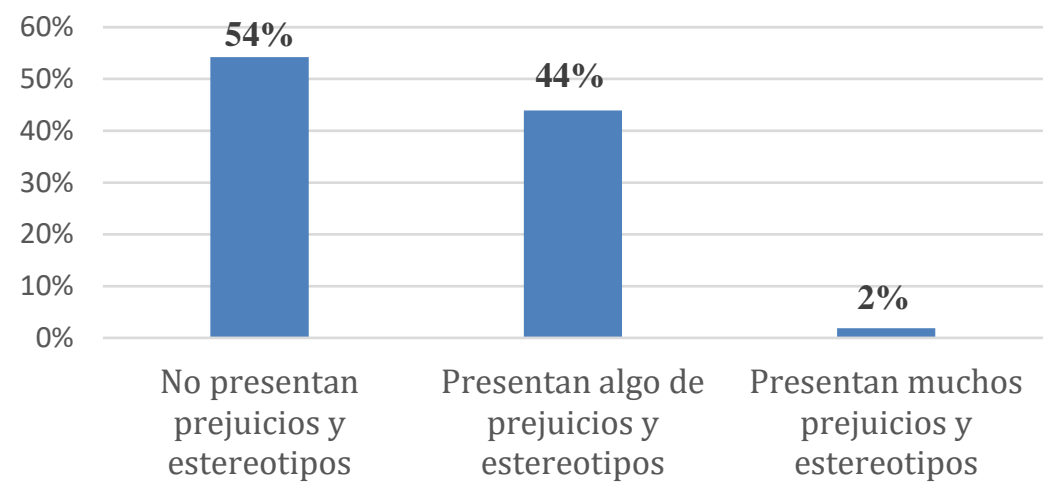

La segunda parte, relativa al análisis de los cuatro grupos bajo los que se agrupan los once ítems muestran lo siguiente:

El primer grupo (1), constituido por estereotipos negativos sobre los musulmanes, aglutina cinco variables redactadas como afirmaciones negativas, revelándose que estas no están muy presentes entre el total del alumnado. Según vemos desglosado (Figura 4), en los enunciados de los ítems se ha vinculado a los musulmanes con términos como sucios, terroristas, machistas o 
“inmigrantes". En este sentido, se ve que la elección de la respuesta 2, referente a la indecisión, es mayoritaria en las cuestiones relativas al machismo y alta en la consideración de "inmigrantes" y "terroristas". Respecto a la consideración de "terroristas", cabe resaltar que, si bien el 10\% que contempla esta apreciación sobre los musulmanes no son musulmanes, sigue siendo alto el porcentaje de musulmanes que se posicionan en el valor indeciso o neutral (2), concretamente el $52 \%$. Con respecto a categorizar a los musulmanes como inmigrantes, si bien es alto el porcentaje de alumnado que tiene claro que esto no es así (43\%), el porcentaje de los indecisos y de los que así lo creen no es desdeñable.

\section{Figura 4}

Estereotipos negativos en torno a los musulmanes. Grupo (1).

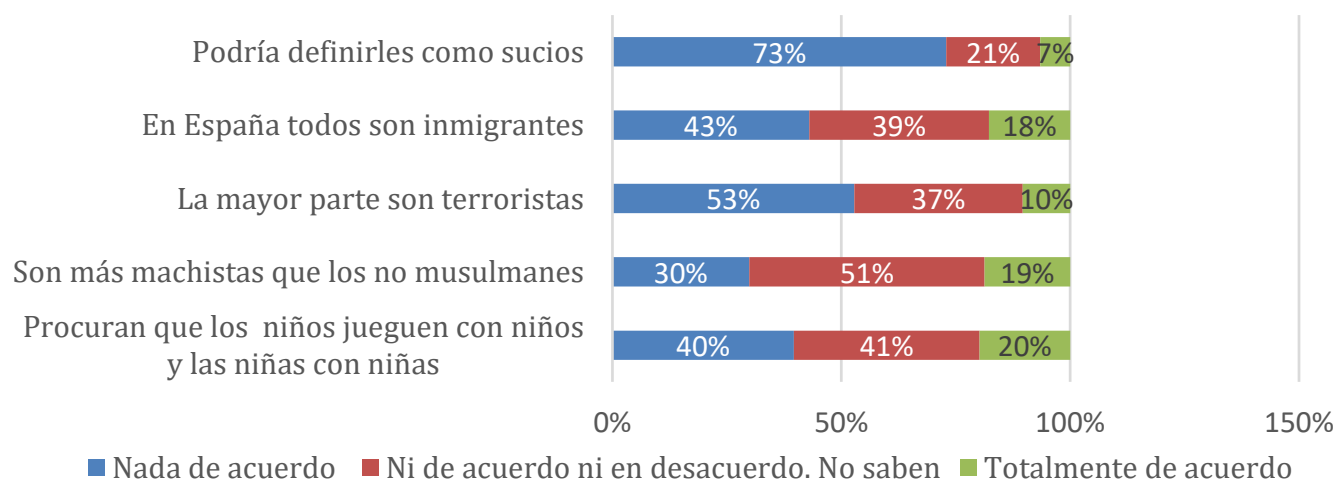

El segundo grupo (2), que alude a la presencia entre el alumnado de prejuicios vinculados a cuestiones culturales, no revela tampoco que, en general, sea muy elevado. Sin embargo, al observarse el desglose de los tres ítems formulados como respuestas positivas (Figura 5), se ve que no queda muy claro entre ellos la diferencia entre musulmán y árabe, ya que, si bien hay muchos que sí lo distinguen (28\%), los porcentajes están bastante igualados con los que no (23\%), y la mitad de la muestra se posiciona ante una indecisión que se podría interpretar como desconocimiento en cuanto a la diferenciación de términos. También se advierte la generalización que se le atribuye a la religión, pues, si bien es mayor el número de alumnado que considera que el islam pueda ser diferente dependiendo del país (31\%), hay un elevadísimo porcentaje que no parece tenerlo claro (58\%), y estos datos incluyen al alumnado musulmán, al que habría que sumarle un $11 \%$ de alumnos que para nada lo contempla.

En esta línea, relacionar la historia y la cultura española con el islam lo hace un 38\% del alumnado, sin embargo, la suma entre los que no lo saben y los que consideran que no hay vinculación, es elevada. Esta lectura resulta inquietante, pues según el currículo de Ciencias Sociales, los contenidos de historia están presente desde 4o de Primaria y Al-Andalus se aborda en 5o curso, además de las cuestiones relativas a la conformación social del territorio español. En definitiva, los resultados de este grupo de ítems parecen indicar que, pese a presentar un porcentaje bajo de prejuicios, al sumar las respuestas del alumnado que no sabe, junto con el que no está de acuerdo con las afirmaciones, se evidencia la necesidad de reflexionar sobre la simplificación y la generalización de los conceptos y términos que aluden a cuestiones culturales 
y religiosas, así como a la comprensión de la multiculturalidad e historia de la sociedad de pertenencia.

\section{Figura 5}

Prejuicios vinculados a cuestiones culturales. Grupo (2)

La historia y la cultura española está muy relacionada con los musulmanes.

La religión musulmana es diferente dependiendo del país.

No todos los musulmanes son árabes

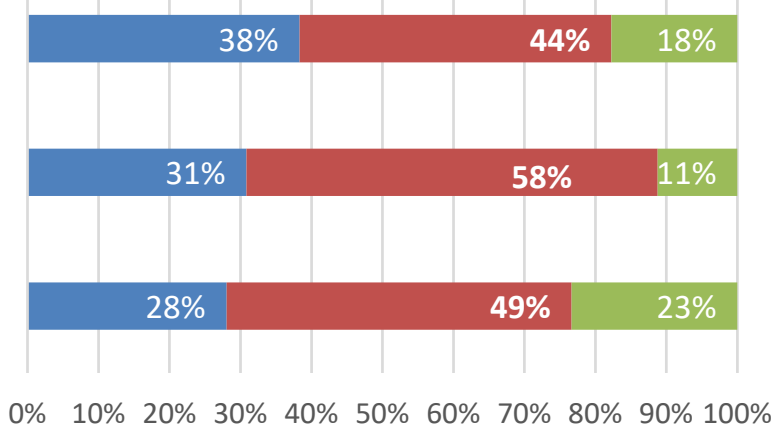

Totalmente de acuerdo $\quad$ Ni de acuerdo ni en desacuerdo. No saben Nada de acuerdo

El tercer grupo (3), compuesto por dos variables, se refiere a las relaciones de amistad y la influencia del islam en las mismas (Figura 6). Es evidente aquí la falta de prejuicios al respecto, pues el alumnado no ha dudado en responder. Además, esto se puede relacionar con la mención que realizan algunos en la pregunta abierta respecto a la igualdad o la normalidad con la que definen, en ocasiones, a los musulmanes.

\section{Figura 6}

Prejuicios presentes en las relaciones con los musulmanes. Grupo (3)

Me da igual la religión de mis compañeros /as

Tengo amigos musulmanes y no musulmanes.

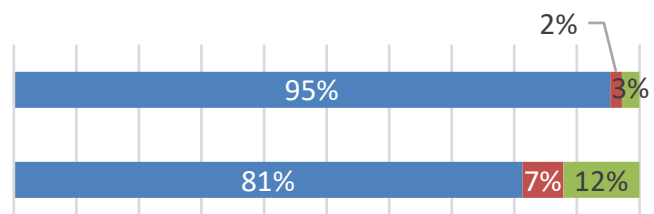

0\% 10\% 20\% 30\% 40\% 50\% 60\% 70\% 80\% 90\% 100\%

- Totalmente de acuerdo $\square$ Ni de acuerdo ni en desacuerdo. No saben $\square$ Nada de acuerdo

Por último, el cuarto grupo (4) presenta un ítem conformado por un comentario que puede oírse en determinados contextos y que supone un prejuicio negativo, por lo que el objetivo es el de conocer si el alumnado lo ha escuchado. Representa un prejuicio negativo porque mezcla y confunde ideas, al asemejarse musulmán con inmigrante. La connotación de inmigrante musulmán que se revela es negativa, pues no es deseado y, además, da a entender que ser musulmán es algo ajeno, que no pertenece a "nuestra" cultura, a "nuestra" identidad, marcando fuertemente el sentido del "ellos" frente a "nosotros". Así, las respuestas (Figura 7) revelan que están muy igualadas y el porcentaje de alumnado que ha dudado ha sido comparativamente menor que con respecto a los ítems anteriores. No obstante, si bien las respuestas en ambos 
grupos de estudiantes siguen ofreciendo la misma polaridad en cuanto a los que sí escuchan este comentario y a los que no, los musulmanes no dudan al respecto y tienen muy clara la respuesta, siendo solo un alumno el que se sitúa en el valor neutral. Esto podría indicar que el valor indeciso entre los no musulmanes responde a una falta de atención ante un comentario que no les afecta directamente.

\section{Figura 7}

El alumnado ha escuchado que "los musulmanes deben volver a su país", Grupo (4)

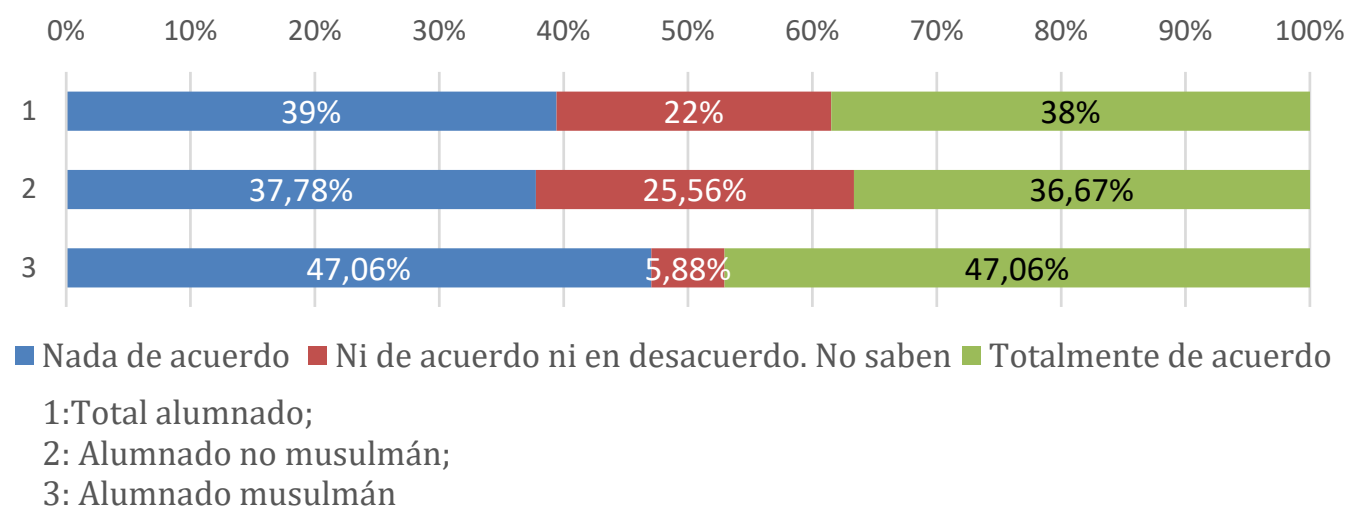

Para intentar comprender algo más de los resultados obtenidos en estos grupos de ítems analizados, se ha recurrido al análisis cualitativo de la pregunta abierta en la que se les pedía a los estudiantes que explicaran qué caracteriza a los musulmanes. Así, primero se ha establecido la frecuencia de las características mencionadas por el alumnado, mostradas en las nubes de palabras de los gráficos 8 y 9, y, posteriormente, estas se han agrupado en cuatro dimensiones: (a) religiosa, (b) cultural, (c) de personalidad y (d) fenotípica, diferenciándose, en ambos casos, las respuestas de los no musulmanes y los musulmanes.

\section{Figura 8}

Nube de palabras con la representación de las características más utilizadas por los no musulmanes

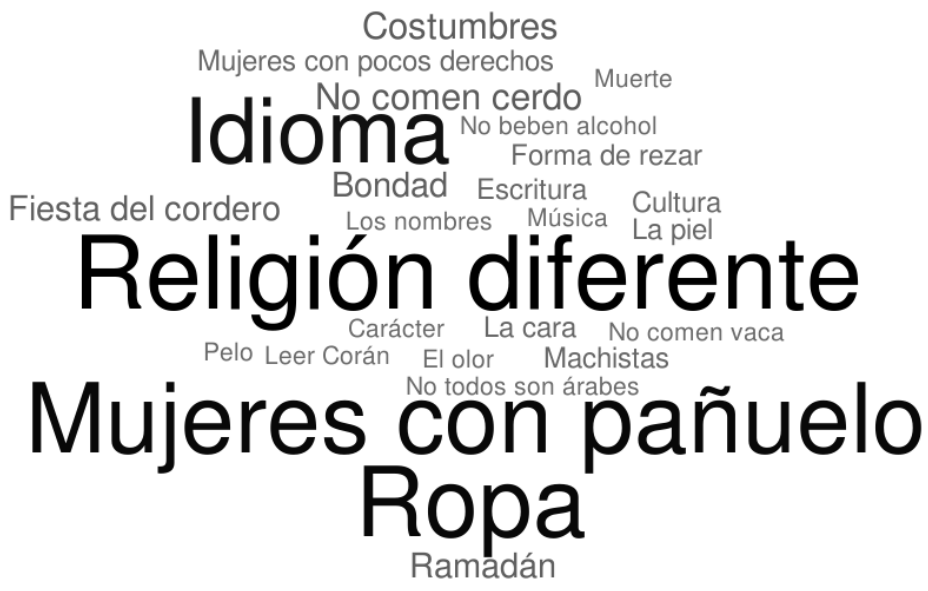




\section{Figura 9}

Nube de palabras con la representación de las características más utilizadas por los musulmanes

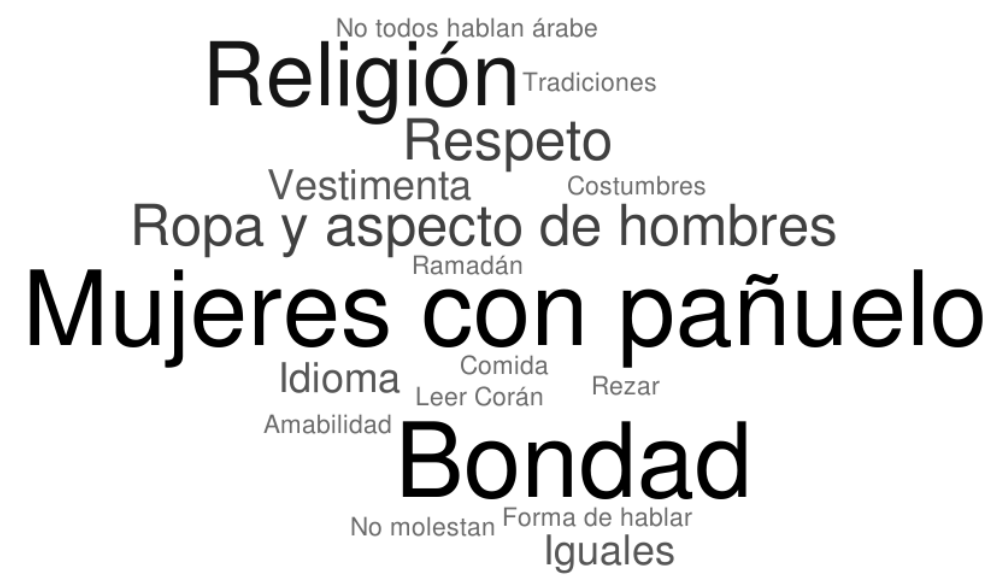

\section{Discusión de resultados}

La generalización de términos, la confusión entre árabe e islam y la consideración del islam como una religión monolítica, donde no se tienen en cuenta los contextos históricos, políticos y culturales, suelen formar parte de los prejuicios en torno a los musulmanes (Durán, 2019; Martín, 2005; Moreras, 2017; van Dijk, 2008). Por tanto, ni todos los árabes son musulmanes, ni todos los musulmanes son árabes. No todos los musulmanes tienen los mismos ritos, ni su práctica e interpretación del islam es igual. Hablar del islam es hablar de una religión que puede incluir un cierto modo de organización social. Según Arbós (2007, p. 198), el término árabe "asume un concepto fundamentalmente lingüístico e histórico cultural y solamente una noción étnica en uso restringido y muy contextualizado". Los términos musulmán e islámico hacen referencia al concepto religioso vinculado con el islam. Musulmán se refiere a personas y grupos sociales que profesan como religión el islam; e islámico, como adjetivo, se utiliza para conceptos, ideas, instituciones o cosas (Arbós, 2007; Gómez, 2019). En cuanto al islamismo, Gómez (2019, p. 197) lo define como "un conjunto de proyectos ideológicos de carácter político cuyo paradigma de legitimación es islámico", así, islamistas, son los militantes políticos.

Esta investigación realizada con alumnado preadolescente que se encuentra en el último curso de Primaria y que al año siguiente comienza la etapa de Secundaria, ha permitido observar que presenta un nivel intermedio de prejuicios y estereotipos negativos con respecto a los musulmanes. Esta imagen se ha manifestado, en ocasiones, de forma igualitaria entre el alumnado musulmán y el no musulmán. Sin embargo, que no haya una presencia excesiva de prejuicios y estereotipos, no quiere decir que no los haya o que no los pueda haber en un futuro en este mismo grupo, pues se adquieren a lo largo de la vida. Son estudiantes que acaban Primaria y están entrando en la adolescencia y, por tanto, se acercan a un periodo crítico en la conformación de su identidad. En este proceso influirá el cambio a un centro de Secundaria y todo lo que ello conlleva en torno a la progresiva incorporación al mundo exterior fuera del núcleo familiar, abriéndose a 
distintos mensajes e ideas por parte de nuevos grupos sociales, medios de comunicación o redes sociales. El acceso a los móviles desde la adolescencia constituye la herramienta ideal para la propagación de prejuicios y estereotipos a través de fake news o bulos, y de la simplificación de la realidad, mediante memes y tweets que carecen de fundamentación. Además, en Secundaria este alumnado cursará asignaturas de historia en las que, dependiendo del enfoque y la didáctica de sus docentes, se podrá contribuir desde esta materia a la construcción positiva o negativa de la identidad del alumnado musulmán que pudiera haber en las aulas, además de ofrecer una visión inclusiva o excluyente del islam en la conformación de la identidad colectiva de todo el alumnado.

La generalización y confusión de términos, así como la homogeneización del islam, se ha observado en los resultados del análisis realizado. Triangular los resultados obtenidos del análisis de los ítems relativos a la presencia de prejuicios y estereotipos negativos de los musulmanes entre el alumnado, con la pregunta abierta, ha permitido interpretar los resultados y, sobre todo, la elección del ítem 2 de indecisión, escogido por gran parte de la muestra. Así, se puede ver que la percepción que tienen de los musulmanes se fundamenta en atributos variados. La categorización de los resultados, permitió estructurarlos en cuatro dimensiones: (a) religiosa, (b) cultural, (c) de personalidad, y (d) fenotípica.

En el caso del alumnado no musulmán, que era mayoritario, la dimensión religiosa (a) ha incluido respuestas como la de que se trata de una religión; las que hacían alusión a aspectos externos y personales que acompañan al sentimiento religioso, como el pañuelo de las mujeres; o descripciones que se han centrado en elementos que forman parte del islam como religión, como no comer cerdo. En la dimensión cultural (b), se han incluido aspectos referidos al idioma o la música; en la dimensión de la personalidad (c), se han resaltado atributos como el machismo y la bondad; y en el marco de la dimensión fenotípica (d), se han incorporado alusiones a la piel o a los rasgos de la cara, teniendo, generalmente, una presencia menor.

Estas dimensiones han estado presentes tanto en los musulmanes como en los no musulmanes, a excepción de la dimensión fenotípica (d), que no se ha contemplado por parte del alumnado musulmán, así como el orden en el que se han dado. La dimensión religiosa (a) ha seguido siendo la primera a la que ha hecho referencia los musulmanes, resaltando, también, la presencia del pañuelo en las mujeres como rasgo definitorio más nombrado. La dimensión cultural (b) ha aparecido, en este caso, en tercer lugar, pues la confusión parece menor en este grupo, pasando la dimensión de personalidad (c) al segundo lugar. Aquí se han observados más adjetivos que calificaban positivamente el carácter de los musulmanes. Posiblemente, estos intentos por destacar aspectos positivos de la personalidad pretenden contrarrestar la percepción de prejuicios y estereotipos sobre los musulmanes que pudieran detectar en su entorno, como muestran las respuestas del ítem del cuarto grupo o al simple hecho de la temática del cuestionario que estaban realizando. Conocer cómo se autodefinen los musulmanes, resulta vital para la promoción de una identidad y una ciudadanía común, así como detectar problemáticas asociadas entre este alumnado a la hora de la construcción de su identidad (Moreras, 2017).

Por último, ha habido algunos comentarios presentes en la caracterización de los musulmanes, entre todo el alumnado, que hacían referencia a la normalidad y a la igualdad, dando muestras de una consideración inclusiva que ha sido refrendada al triangularse con las respuestas 
del tercer grupo. En general, el alumnado de esta edad no presenta problemas para relacionarse entre ellos. Por el contrario, y de forma muy minoritaria, ha habido algunas respuestas que han coincidido en que "son diferentes a nosotros", viéndose aquí, claramente, ese "nosotros" frente al "ellos".

Existen algunos trabajos que muestran la percepción que tienen los españoles de los marroquíes y de los musulmanes. En el caso de la investigación dirigida por Prats (2001) sobre la percepción y conocimientos que muestra un grupo de adolescentes españoles de $4^{\circ}$ de la ESO, hacia Europa, la Unión Europea, los europeos y otras personas que forman parte de ella, como los marroquíes, se evidencia una actitud de rechazo, con presencia de prejuicios y estereotipos negativos hacia ellos. Así, parece que los adolescentes les perciben como pobres, con una lengua, cultura y religión muy diferentes, poniendo de relieve, incluso, algunos rasgos hostiles y xenofóbicos hacia ellos.

Por su parte, Alaminos-Fernández y Alaminos-Fernández (2012), muestran los resultados de un estudio en relación con los datos recogidos en la encuesta Global Attitudes, realizada en 2012 por la fundación PEW, a personas no musulmanas de Gran Bretaña, Francia, Alemania y España, sobre la asociación que realizaban de determinados atributos con los musulmanes. En general, los datos mostraron que los españoles son los que mayores porcentajes de estereotipos negativos tenían sobre los musulmanes, a través de atributos como violentos, fanáticos, intolerantes o irrespetuosos con las mujeres, entre otros. Sin embargo, en cuanto al discurso islamofóbico presente en los medios de comunicación, Durán (2019) concluye que a pesar de que este se refleje en todos los países europeos, en comparación, parece que la visión española es la menos racista.

Estos estudios, junto a los que han tratado de denunciar la islamofobia presente en los medios de comunicación y, sobre todo, a aquellos que han querido destapar los prejuicios y estereotipos vinculados a la enseñanza de la historia (Martín, 1998; 2005; Martín, Valle y López, 1996; Parra, 2007), revelan la necesidad de reflexionar, desde la enseñanza de las ciencias sociales y la historia, acerca de la visión que se le otorga al islam y a los musulmanes.

La explicación ante una, relativamente, baja presencia de prejuicios y estereotipos sobre los musulmanes en el alumnado de la muestra, que presenta una diversidad cultural, podría deberse, además de a la edad, hecho ya comentado, al contexto histórico y social del archipiélago y, particularmente, de la isla y el municipio. Canarias está ubicada en el Atlántico, a poco más de 100 kilómetros del continente africano y, como en el resto del estado, la población extranjera proviene, mayoritariamente, de Europa, América y África, destacando, de este último la presencia marroquí. Su posición geoestratégica, ha propiciado un contacto histórico de la población canaria con los tres continentes, tanto a través de actividades diversas con la costa africana, como por la migración de los canarios a antiguos territorios españoles en América o África. Así, la población canaria tiene una larga trayectoria en la convivencia con diferentes culturas, y la diversidad cultural del municipio se observa en las procedencias de los progenitores del alumnado. Este factor, es posible, que haya configurado una sociedad más abierta y con menos prejuicios y estereotipos hacia otras culturas y otras religiones.

Sería interesante profundizar en esta investigación a través de una comparación con el alumnado que finaliza Secundaria, así como con el de otros territorios con contextos históricos y 
sociales diferentes, porque como mencionan García y Goenechea (2009, p. 49) la diversidad cultural "no puede analizarse únicamente en relación con la inmigración y la multiculturalidad, sino desde un marco más amplio de cambios sociales, económicos, políticos y culturales".

\section{Conclusiones}

Los prejuicios y los estereotipos juegan un papel esencial en la construcción de quienes somos y en la concepción que tenemos de nosotros mismos y de los "otros", y para lograr una convivencia igualitaria y respetuosa debemos tomar conciencia de ellos y combatirlos. La diversidad cultural social queda configurada por las migraciones y por el contexto histórico y social, y desde la educación, en general, y desde la enseñanza de la historia, en particular, los docentes tenemos un papel esencial en el proceso de construcción identitario de nuestro alumnado.

La historia de Europa y de España no se entiende sin la presencia del islam. Si se quiere caminar hacia una ciudadanía global, se debe dejar de considerar e interpretar al islam y a los musulmanes como un todo compacto y monolítico que se definen únicamente por su religiosidad o por la visibilidad de los elementos que puedan caracterizar la religión y, en esta línea, tampoco se deben confundir los orígenes y los aspectos culturales con los religiosos, aunque, en ocasiones, vayan entrelazados. Desde las aulas de historia conviene recordar que el termino musulmán constituye una referencia religiosa que se relaciona con otras categorías, formando parte así de la multiplicidad de pertenencias que configuran la identidad de las personas. La perspectiva que se adopte a la hora de afrontar el papel del islam en la enseñanza de la historia, tomando conciencia de la cantidad de prejuicios y estereotipos que conforman la visión que, tanto de la religión, como de los musulmanes y de lo árabe se tiene desde Occidente (Said, 2003), supondrá fomentar una identidad inclusiva o no, del alumnado musulmán y no musulmán, además de crear las condiciones para fomentar el pensamiento histórico.

Así, la enseñanza de la historia debe promover un pensamiento social a través de cuestiones socialmente vivas, que ayuden al alumnado a reflexionar sobre la realidad, sobre quiénes somos y hacia dónde queremos ir, fomentando un pensamiento crítico que permita alcanzar una ciudadanía democrática, activa y global, para lo cual resulta vital tratar los prejuicios y estereotipos en las ideas previas (Pagès, 2019; Pagès y Santisteban, 2010; Santisteban, 2019; Valls, 2011).

\section{Referencias bibliográficas}

Abdallah-Pretceille, M. (2001). La educación intercultural. Barcelona: Idea Books.

Abu Zayd (2012). Religiones: de la fobia al entendimiento. En G. Martín y R. Grosfoguel (Eds.) La islamofobia a debate. La genealogía del miedo al islam y la construcción de los discursos antiislámicos (pp. 11-33). Madrid: Casa Árabe.

Alaminos-Fernández, P., y Alaminos-Fernández, A. (2020). Ethnocentrism and Cultural Stereotypes of Muslims in Spain. OBETS. Revista de Ciencias Sociales, 15(1), 17-42. https://doi.org/10.14198/OBETS2020.15.1.01 
Alaminos-Fernández, A., y Alaminos-Fernández, P. (2012). Estereotipos sobre los musulmanes en España, Gran Bretaña, Francia y Alemania. VIII Jornadas Internacionales de Modelado Estructural en el Análisis de la Realidad Social. Alicante: Universidad de Alicante, 1-18.

Alcántara-Pla, M., y Ruiz-Sánchez, A. (2017). The framing of muslims in the Spanish internet. Lodz Papers in Pragmatics, 13(2), 261-283. https://doi.org/10.1515/lpp-2017-0013

Allport, G.W. (1981). La naturaleza del prejuicio. Buenos Aires: Editorial Universitaria de Buenos Aires.

Arbós, F. (2007). Variantes de los procesos de integración de los musulmanes del mundo árabe en la cultura europea. En O. Salazar y M. Torres (Eds.) La inclusión del otro. Más allá de la tolerancia (pp. 195-224). Córdoba: Diputación de Córdoba y Universidad de Córdoba.

Atienza, E. (2007). Discurso e ideología en los libros de texto de ciencias sociales. Discurso y Sociedad, 1(4), 543-574.

Bartolomé, M., y Cabrera, F. (2003). Sociedad multicultural y ciudadanía: Hacia una sociedad y ciudadanía interculturales. Revista de Educación, Extra 1, 33-56.

Bartolomé, M. (2002). El reto de las migraciones en sociedades multiculturales, desde la perspectiva de la Educación. En C. Morano (Coord.) Fe y cultura: encuentros, desencuentros y retos actuales (pp. 201-243). Universidad Pontificia de Salamanca: Salamanca.

Bordignon, N.A. (2005). El desarrollo psicosocial de Eric Erikson. El diagrama epigenético del adulto. Revista Lasallista de Investigación, 2(2), 50-63.

Bueno, G. (2001). Identidades y educación. La perspectiva de un filósofo. En J. Estepa, F. Friera y R. Piñeiro (Eds.) Identidades y territorios: un reto para la didáctica de las Ciencias Sociales (pp. 5-55). Oviedo: KRK y AUPDCS.

Cabrera, F.A. (2002). Hacia una nueva concepción de la ciudadanía en una sociedad multicultural. En M. Bartolomé (Coord.) Identidad y ciudadanía. Un reto para la educación intercultural (pp. 79-104). Madrid: Narcea S.A. de Ediciones.

Carretero, M., Castorina, J.A., Sarti, M., Van Alphen, F., y Barreiro, A. (2013). La Construcción del conocimiento histórico. Propuesta educativa, 39, 13-23.

Carretero, M., y Montanero, M. (2008). Enseñanza y aprendizaje de la Historia: Aspectos cognitivos y culturales. Cultura y Educación, 20(2), 133-142. https://doi.org/10.1174/113564008784490361

Casas, M. (1999). Cambio de actitudes en contextos interculturales en Barcelona. Scripta Nova. Revista Electrónica de Geografía y Ciencias Sociales, 44.

Del Olmo, M. (2005). Prejuicios y estereotipos: Un replanteamiento de su uso y utilidad como mecanismos sociales. Revista de Educación, 7, 13-23.

Durán, R. (2019). El encuadre del islam y los musulmanes: La cobertura periodística en España. Revista de Estudios Internacionales Mediterráneos, 26, 156-18. https://doi.org/10.15366/reim2019.26.010

Erikson, E. (1972). Notas autobiográficas sobre la crisis de identidad. México: Siglo XXI.

Flick, U. (2015). El diseño de la investigación cualitativa. Madrid: Morata.

García, J.A., y Goenechea, C. (2009). Educación intercultural. Análisis de la situación y propuestas de mejora. Madrid: Wolters Kluwer. 
García, J., Aguilera, J.R., y Castillo, A. (2011). Guía técnica para la construcción de escalas de actitud. Odiseo, revista electrónica de pedagogía, 8(16), 1-13.

Geisser, V. (2012). Islamofobia: ¿una especificidad francesa en Europa? En G. Martín y R. Grosfoguel (Eds.) La islamofobia a debate. La genealogía del miedo al islam y la construcción de los discursos antiislámicos (pp. 61-73). Madrid: Casa Árabe.

Gómez, L. (2019). Diccionario de islam e islamismo. Madrid: Trotta.

Gómez, C.J., y García, F. (2017). La difícil transposición didáctica. Un estudio comparativo de la construcción de estereotipos sociales desde la historiografía al aula (España-Francia). $\begin{array}{lllll}\text { OBETS. Revista de } & \text { Ciencias }\end{array}$ https://doi.org/10.14198/OBETS2017.12.2.02

González-Monfort, N., y Santisteban, A. (2020). Alfabetización crítica para interpretar problemas. Íber: Didáctica de las ciencias sociales, geografía e historia, 99, 39-45.

Guichot-Reina, V. (2002). Identidad, ciudadanía y educación: Del multiculturalismo a la interculturalidad. Cuestiones pedagógicas: Revista de Ciencias de la Educación, 16, 25-44.

Kem-Mekah, 0. (2016). África en el imaginario de la ciudadanía occidental. El caso de España. Humania del Sur: Revista de Estudios Latinoamericanos, africanos y asiáticos, 11(22), 11-22.

López, B. (2013). España y el mundo árabe-islámico: historia de una multiplicidad de relaciones y encuentros. En O. Orozco y G. Alonso (Eds.) El Islam y los musulmanes hoy. Dimensión internacional y relaciones con España (pp. 11-28). Madrid: Escuela diplomática y Casa Árabe.

Maalouf, A. (2009). Identidades asesinas. Madrid: Alianza Editorial.

Manzano. E. (2013). El islam en la península ibérica. En O. Orozco y G. Alonso (Eds.) El Islam y los musulmanes hoy. Dimensión internacional y relaciones con España (pp. 211-226). Madrid: Escuela Diplomática y Casa Árabe.

Marín, M.A. (2002). La construcción de la identidad en la época de la mundialización y los nacionalismos. En M. Bartolomé (Coord.) Identidad y ciudadanía. Un reto para la educación intercultural, (pp. 27-50). Madrid: Narcea S.A. de Ediciones.

Martín, G. y Grosfoguel, R. (2012). Introducción. En G. Martín y R. Grosfoguel (Eds.) La islamofobia a debate. La genealogía del miedo al islam y la construcción de los discursos antiislámicos (pp. 7-11). Madrid: Casa Árabe.

Martín, G. (2012). La islamofobia inconsciente. En G. Martín y R. Grosfoguel (Eds.) La islamofobia a debate. La genealogía del miedo al islam y la construcción de los discursos antiislámicos (pp. 35-46). Madrid: Casa Árabe.

Martín, G. (2005). Mujeres musulmanas: entre el mito y la realidad. En J.C. Checa y Olmos (Ed.) Mujeres en el camino. El fenómeno de la migración femenina en España (pp. 193-220). Barcelona: Icaria.

Martín, G. (1998). Entre el tópico y el prejuicio. El islam y el mundo árabe en el sistema educativo español. Revista de Educación, 316, 151-162.

Martín, G., Valle, B, y López, M.A. (1996). El islam y el mundo árabe. Guía didáctica para profesores y formadores. Madrid: Agencia Española de Cooperación Internacional.

Mercado, A., y Hernández, A.V. (2010). El proceso de construcción de la identidad colectiva. Convergencia. Revista de Ciencias Sociales, 17(53), 229-251. 
Morales, P. (2011). Guía para construir cuestionarios y escalas de actitudes. Madrid: Universidad Pontificia de Comillas.

Moreras, J. (2017). ¿Qué islam para qué Europa? Hacia una antropología del islam posmigratorio en Europa. Revista CIDOB d'Afers Internacionals, 115, 13-37. https://doi.org/10.24241/rcai.2017.115.1.13

Moualhi, D. (2000). Mujeres musulmanas: Estereotipos occidentales versus realidad social. Papers: revista de sociología, 291-304. https://doi.org/10.5565/rev/papers/v60n0.1044

Navarro, L. (2002). Islamofobia y sexismo. Las mujeres musulmanas en los medios de comunicación occidentales. En G. Martín y R. Grosfoguel (Eds.) La islamofobia a debate. La genealogía del miedo al islam y la construcción de los discursos antiislámicos (pp. 141-166). Madrid: Casa Árabe.

Observatorio Andalusí (2020). Estudio demográfico de la Población Musulmana. Exploración estadística del censo de ciudadanos musulmanes en España referido a fecha 31/12/2019. Madrid: UCIDE.

Observatorio Andalusí (2019). Informe especial 2018: Institución para la observación y seguimiento de la situación del ciudadano musulmán y la islamofobia en España. Incidencias e islamofobia. Madrid: UCIDE.

Pagès, J. (2019). Ciudadanía global y enseñanza de las Ciencias Sociales: Retos y posibilidades para el futuro. REIDICS. Revista de Investigación en Didáctica de las Ciencias Sociales, 5, 5-22. https://doi.org/10.17398/2531-0968.05.5.

Pagès, J. y Santisteban, A. (2010). La educación para la ciudadanía y la enseñanza de las ciencias sociales, la geografía y la historia. Iber: Didáctica de las ciencias sociales, geografía e historia, 64, 8-18.

Parra, D. (2007). Islam e identidad en la escuela franquista. Imágenes y tópicos a través de los manuales. Didáctica de las Ciencias Experimentales y Sociales, 21, 15-32.

Prats, J. (Dir.). (2001). Los jóvenes ante el reto europeo. Barcelona: Fundación La Caixa.

Rodrigues de Mendonça, M., y Rodríguez-Díaz, R. (2017). Medios de comunicación y religiones minoritarias en España: judaísmo, islamismo y protestantismo. OBETS. Revista de Ciencias Sociales, 12(2), 489-513. https://doi.org/10.14198/OBETS2017.12.2.07

Rodríguez-Lestegás, F. (2008). La construcción de identidades en la sociedad actual: Un desafío para la educación y para la democracia. Revista española de pedagogía, 239, 85-102.

Sabariego, M. y Bisquerra, R. (2012). Fundamentos metodológicos de la investigación educativa. En R. Bisquerra (Coord.). Metodología de la investigación educativa, (pp. 19-50). Madrid: La Muralla.

Saleh, W. (2008). La imagen de árabes y musulmanes en los libros de texto. CONTRA/ RELATOS desde el Sur, 4(5-6), 125-136.

Sáiz, J., y López, R. (2012). Aprender y argumentar España. La visión de la identidad española entre el alumnado al finalizar el bachillerato. Didáctica de las Ciencias Experimentales y Sociales, 26, 95-120. https://doi.org/10.7203/dces.26.1933 
Santisteban, A., Díez-Bedmar, M.C., y Castellví, J. (2020). La alfabetización crítica digital del futuro profesorado en tiempos de Twitter. Culture and Education, 32(2), 185-212. https://doi.org/10.1080/11356405.2020.1741875

Santisteban, A. (2019). La enseñanza de las Ciencias Sociales a partir de problemas sociales o temas controvertidos: Estado de la cuestión y resultados de una investigación. El futuro del Pasado, 10, 57-79.

Said, W.E. (2003). Orientalismo. Barcelona: Debolsillo.

Turner J. (2010). Towards a cognitive redefinition of the social group. En H. Tajfel (Ed.) Social Identity and Intergroup Relations (pp.15-40). Cambridge: Cambridge University Press.

Valls, R. (2012). La presencia del islam en los actuales manuales españoles de historia. Íber Didáctica de las Ciencias Sociales, Geografía e Historia, 70, 59-66.

Valls, R. (2011). La multiculturalidad en la enseñanza de la Historia y el desajuste entre intenciones educativas y prácticas escolares: Los retos del presente y del futuro inmediato. Educar em Revista, 42, 73-94. https://doi.org/10.1590/S0104-40602011000500006

Van Dijk, T.A. (2008). Racismo, Prensa e Islam. Derechos Humanos y Diversidad Cultural y Religiosa, $5,17-20$. 